\title{
Handle with care: A systematic review on frailty in cardiac care and its usefulness in heart transplantation
}

\author{
Oliver Mauthner ${ }^{\mathrm{a}, *}$, Veerle Claes ${ }^{\mathrm{a}, \mathrm{b}}$, Mieke Deschodt ${ }^{\mathrm{a}, \mathrm{b}}$, Sunita R. Jha ${ }^{\mathrm{c}, \mathrm{d}}$, Sandra Engberg ${ }^{\mathrm{e}}$, \\ Peter S. Macdonald ${ }^{\text {c,f }}$, Phillip J. Newton ${ }^{d}$, Sabina De Geest ${ }^{\mathrm{a}, \mathrm{b}}$ \\ a Institute of Nursing Science, Faculty of Medicine, University of Basel, Switzerland \\ ${ }^{\mathrm{b}}$ Academic Centre for Nursing and Midwifery, Department of Public Health and Primary Care, KU Leuven, Belgium \\ ${ }^{c}$ Heart Transplant Program, St Vincent's Hospital, Sydney, Australia \\ d Centre for Cardiovascular and Chronic Care, Faculty Health, University of Technology Sydney \\ e School of Nursing, University of Pittsburgh, USA \\ ${ }^{\mathrm{f}}$ Victor Chang Cardiac Research Institute, Sydney, NSW
}

\section{A B S T R A C T}

Background: There is growing consensus that frailty, a state of vulnerability and a decline in functioning across multiple physiological body systems, is a valuable criterion to guide clinicians' risk prediction for poor outcomes in adult transplant candidates. In its 2016 listing criteria for heart transplantation the International Society for Heart Lung Transplantation recommends frailty assessment. We aimed to summarize the usefulness of frailty assessment in heart transplant candidates or recipients reported throughout the literature.

Methods: We performed a systematic literature search in PubMed to identify papers reporting on frailty in transplantation, chronic heart failure, and ventricualr assist device implantation published over the last 10 years in English. Additionally, a hand search was conducted, including manually searching the reference lists and a citation search of relevant papers.

Results: Eleven primary research articles were included in this systematic review. Frailty is a risk factor for morbidity, hospitalization, and mortality in patients with advanced heart failure and individuals being considered for ventricualr assist device implantation. Of the patients being considered for transplantation, 33\% are frail. The Frailty Phenotype by Fried is a particularly useful tool to quickly identify higher risk patients for adverse outcomes. Conclusion: A lack of standardization and limited evidence on frailty in transplantation limit its use as a definitive listing criterion. Future research efforts should focus on systematic integration of frailty measures in transplant practice.

(c) 2017 Elsevier Inc. All rights reserved.

\section{Introduction}

Frailty is one of the most critical issues for healthcare due to its inherent relationship with poor clinical outcomes [1-3]. It has been defined as a cumulative decline across physiological body systems, depleting a person's ability to maintain homeostasis when faced with stressors [4-6]. Individuals undergoing organ transplantation face several major stressors, and frail transplant patients are more likely to experience sudden disproportionate deteriorations in health status compared with non-frail patients [4-6]. Following these recent insights, in their 10-year update of assessment criteria for heart transplantation the International Society for Heart Lung Transplantation (ISHLT) has recommended that patients being evaluated for heart transplantation be assessed for frailty [7]. Frailty assessment is deemed particularly relevant since respectively $20 \%$ and $17 \%$ of heart transplant candidates and recipients in the United States of America (US) are $\geq 65$ years of age, with

\footnotetext{
* Corresponding author at: Institute of Nursing Science, Faculty of Medicine, University of Basel, Bernoullistrasse 28, CH-4056, Basel, Switzerland. Tel.: +41 612670954 (Business), +4176 4193360 (Home); fax: +41612670955.

E-mail address: oliver.mauthner@unibas.ch (O. Mauthner).
}

similar figures reported in Europe [8-10]. It is postulated that frailty can provide an important contribution to the limited evidence base to guide clinical decision-making for transplant candidacy and optimal clinical management for this older cohort [11,12]. Since frailty assessment is endorsed by ISHLT, it is timely that transplant clinicians understand the concept of frailty, its measurement in clinical practice, and outcomes. Therefore, we aimed to summarize the usefulness of frailty assessment in heart transplant candidates, recipients, and individuals being considered for destination therapy. This systematic review is expanding on a previous work on frailty in heart failure patients [13] to include specific new subgroups of populations, and to identify new evidence up to the present time.

\subsection{Frailty: two distinct conceptual models that serve different purposes}

Two main conceptual approaches to measuring frailty have been developed over the past 15 years. Even though there is now broad agreement on the definitions and conceptualization of the syndrome, there is no consensus on which instrument is best suited to measure frailty. [14-16] The Frailty Phenotype (FP) focuses on physical aspects of frailty 
Table 1

Fried frailty phenotype instrument [4].

\begin{tabular}{|c|c|}
\hline Domain & Assessment and scoring \\
\hline Grip Strength & $\begin{array}{l}\text { Assessment: Grip strength as measured by the hand-held Jamar dynamometer (Sammons Preston Inc. Boiling Brook, IL), } \\
\text { which has established test-retest, inter- and intra-rater reliability [68]. Stratified by gender and body mass index (BMI) quartiles: } \\
\text { Men Cutoff for grip strength }(\mathrm{kg}) \text { criterion for frailty } \\
\text { BMI } \leq 24 \leq 29 \\
\text { BMI } 24.1-26 \leq 30 \\
\text { BMI } 26.1-29 \leq 30 \\
\text { BMI }>28 \leq 32 \\
\text { Women } \\
\text { BMI } \leq 23 \leq 17 \\
\text { BMI } 23.1-26 \leq 17.3 \\
\text { BMI } 26.1-29 \leq 18 \\
\text { BMI }>29 \leq 21 \\
\text { Scoring: } 1 \text { point if weakness is present. }\end{array}$ \\
\hline Walk Time & $\begin{array}{l}\text { Assessment: stratified by gender and height (gender-specific cutoff a medium height). } \\
\text { Men Cutoff for Time to Walk } 15 \mathrm{f} \text {. criterion for frailty } \\
\text { Height } \leq 173 \mathrm{~cm} \geq 7 \mathrm{~s} \\
\text { Height }>173 \mathrm{~cm} \geq 6 \mathrm{~s} \\
\text { Women } \\
\text { Height } \leq 159 \mathrm{~cm} \geq 7 \mathrm{~s} \\
\text { Height }>159 \mathrm{~cm} \geq 6 \mathrm{~s} \\
\text { Scoring: } 1 \text { point if slowness is present. }\end{array}$ \\
\hline Low level of physical activity & $\begin{array}{l}\text { Assessment: through } 1 \text { closed-ended question: 'How often do you engage in activities that require a low or moderate level of energy, } \\
\text { such as walking, chores (moderately strenuous), mowing the lawn, raking, gardening, hiking, jogging, exercise cycling, dancing, aerobics, } \\
\text { bowling, golf, tennis, racquetball, calisthenics, swimming. Kcals per week expended are calculated using standardized algorithm, } \\
\text { This variable is stratified by gender. } \\
\text { Scoring: } 1 \text { point if: } \\
\text { Men: Kcals of physical activity per week }<383 \text { are frail } \\
\text { Women: Those with Kcals per week }<270 \text { are frail }\end{array}$ \\
\hline Exhaustion & $\begin{array}{l}\text { Assessment: the following two statements are read: 'I felt that everything I did was an effort?' and 'I could not get going?' } \\
\text { "How often in the week did you feel that way?" (Answer option: } 0=\text { rarely or none of the time ( }<1 \text { day), } 1=\text { some or a little of the time } \\
(1-2 \text { days), } 2=\text { a moderate amount of the time ( } 3-4 \text { days), or } 3=\text { most of the time. A response of " } 2 \text { " or " } 3 \text { " to either one or } \\
\text { both questions is considered as exhaustion and categorized as frail. } \\
\text { Scoring: } 1 \text { point if exhaustion is present. }\end{array}$ \\
\hline Weight loss & $\begin{array}{l}\text { Assessment: through } 1 \text { closed-ended question: 'In the last year, have you lost more than } 10 \mathrm{lb} \text { unintentionally } \\
\text { (i.e., not due to dieting or exercise)?' (If yes, then frail for weight loss criterion. } \\
\text { Scoring: } 1 \text { point if weight loss is present. }\end{array}$ \\
\hline Overall score & $\begin{array}{lll}\text { Non-frail: } 0 & \text { Pre-frail: } 1-2 & \text { Frail: } 3-5\end{array}$ \\
\hline
\end{tabular}

(Table 1). It is an internationally recognized and widely applied conceptual framework of frailty, which was first proposed and psychometrically tested in the Cardiovascular Health Study in 2001, a large cohort study in community dwelling older adults in the US [4,17-19]. This phenotype consists of five components that capture a decline in physiological reserve: (1) unintentional weight loss (10 lb in the past year); (2) self-reported exhaustion; (3) a low level of physical activity; (4) slow walk speed; and (5) reduced grip strength, and categorizes individuals as non-frail $(0 / 5)$, pre-frail $(1-2 / 5)$, or frail $(\geq 3 / 5)[4-6]$. The FP is a widely used approach for assessing frailty in a variety of chronically ill populations [20] and is endorsed for integration in the preoperative assessment for older surgical patients by the American College of Surgeons [16] and the American Geriatric Society [21].

Rockwood and colleagues used the Canadian Study of Health and Aging to develop and validate the Frailty Index (FI) in 2001 [22-25]. The FI is based on a count of up to 70 deficits, including comorbidities, physical and cognitive impairments, psychosocial factors and common geriatric syndromes (e.g. urinary incontinence, fall risk, delirium) (Table 2) [6,24-26]. The understanding here is that frailty is a condition that encompasses medical, functional and psychosocial domains, and defines an individuals' severity of frailty by the proportion of possible deficits present [27]. A total score from 0.0 (no frailty) to 1.0 (highest severity of frailty) is derived [24].

Frailty measurement is not yet routinely applied in transplantation and is frequently judged from the end of the bed, under the assumption "I know it when I see it". However, this end-of-the-bed assessment is an inadequate substitution for objectively assessing frailty using standardized measurements in acute cardiology and hemodialysis [28,29]. As clinicians tend to underestimate frailty in clinical settings, the use of standardized, reliable and valid frailty screening and assessment tools is imperative $[28,29]$. Many different frailty measurements exist that have not been extensively validated, applied across various age- and disease groups, or compared against each other in their capacity to predict adverse outcomes. This heterogeneity in approaches provides challenges for clinicians to choose an appropriate instrument to routinely apply frailty measurement in clinical practice $[16,20]$. Some authors suggest that the FI is conceptually less well defined, as deficits captured include disabilities and comorbidities, concepts which co-occur with, yet are distinct from frailty [17]. The FP is reported to recognize frailty as a distinct medical condition that is separate from disability and

Table 2

Frailty Index.

\begin{tabular}{ll}
\hline Domain & Assessment \\
\hline Mobility & Walking speed \\
& Number of falls in the past six months \\
Cognition & History of dementia \\
& Mini-Cog Test or Mini-Mental Status Exam \\
Function & Dependency in activities of daily living \\
Exhaustion & Energy level \\
Burden of chronic disease & Charlson Index \\
& $>5$ chronic medications \\
Nutritional status & $>10$ lb weight loss in the past 6 months \\
& low albumin, poor appetite \\
Mood & Depression, Sadness, Anxiety \\
Social vulnerability & Presence of social support \\
& Lack of interactions with other people
\end{tabular}

Scoring for frailty: classify each characteristic as present or absent based on standard cutoff points, sum the number of abnormal frail characteristics and divide by the number of total assessed characteristics. 
comorbidities, which provides a major advantage for using this conceptual model.

\section{Methods}

\subsection{Identification of relevant papers}

We performed a systematic review of articles published in English over the last ten years in PubMed, followed by a citation search. A search string was built combining MeSH terms and free text words related to 'frailty' and 'transplantation' (Fig. 1). Additionally, the reference lists of studies meeting eligibility criteria were screened for relevant papers that might have been missed through the electronic search.

\subsection{Selection of relevant papers}

We included papers reporting on frailty in heart transplantation, chronic heart failure and ventricualr assist device (VAD) implantation. Heart failure patients requiring either bridge-to-transplant or destination VAD therapy are included in this review due to the very limited evidence pertaining to cardiac transplantation alone. Quantitative studies were included if a defined measure of frailty was assessed in a cohort of heart transplant candidates or recipients, heart failure patients, or VAD recipients. Qualitative studies, doctoral theses, books and book chapters, and case studies were excluded.

The titles and abstracts of potentially relevant papers were screened using the predefined inclusion and exclusion criteria. Then the full text articles were obtained from all abstracts meeting inclusion criteria and were further screened for eligibility. Two researchers (OM, VC) independently performed the selection and inclusion of articles, with differences being resolved through discussion with a third member (SRJ).

\subsection{Data extraction and summarizing}

An initial data-charting format was developed by two researchers $(\mathrm{OM}, \mathrm{VC})$. Iterative discussions within the research team guided small adjustments during the data charting process. The final version entailed information concerning prevalence, morbidity, and mortality about frailty in transplantation, chronic heart failure, and VAD implantation. Data from the included studies were extracted by one researcher (OM) and double-checked by a second reviewer (VC). The methodological quality of the studies was checked using The Strengthening the Reporting of Observational Studies in Epidemiology (STROBE) instrument of the Equator Network. The review process was reported based on the guidelines of the Preferred Reporting Items for Systematic Reviews and Meta-Analysis (PRISMA).

\section{Results}

The database search produced 1713 articles for screening (Fig. 1). After screening of titles, abstracts and full texts, 11 studies [30-40] were included and summarized in this paper (Table 3). Although over the past 10 years a rapid growing body of evidence has highlighted frailty as a highly prevalent and novel predictor for clinically relevant adverse outcomes in general [20], only one study assessing frailty in patients referred for heart transplantation could be identified [30]. Nevertheless, frailty has been examined more intensively in the related field of chronic heart failure, as well as mechanical circulatory support implant and is thus included in this review [31-40].

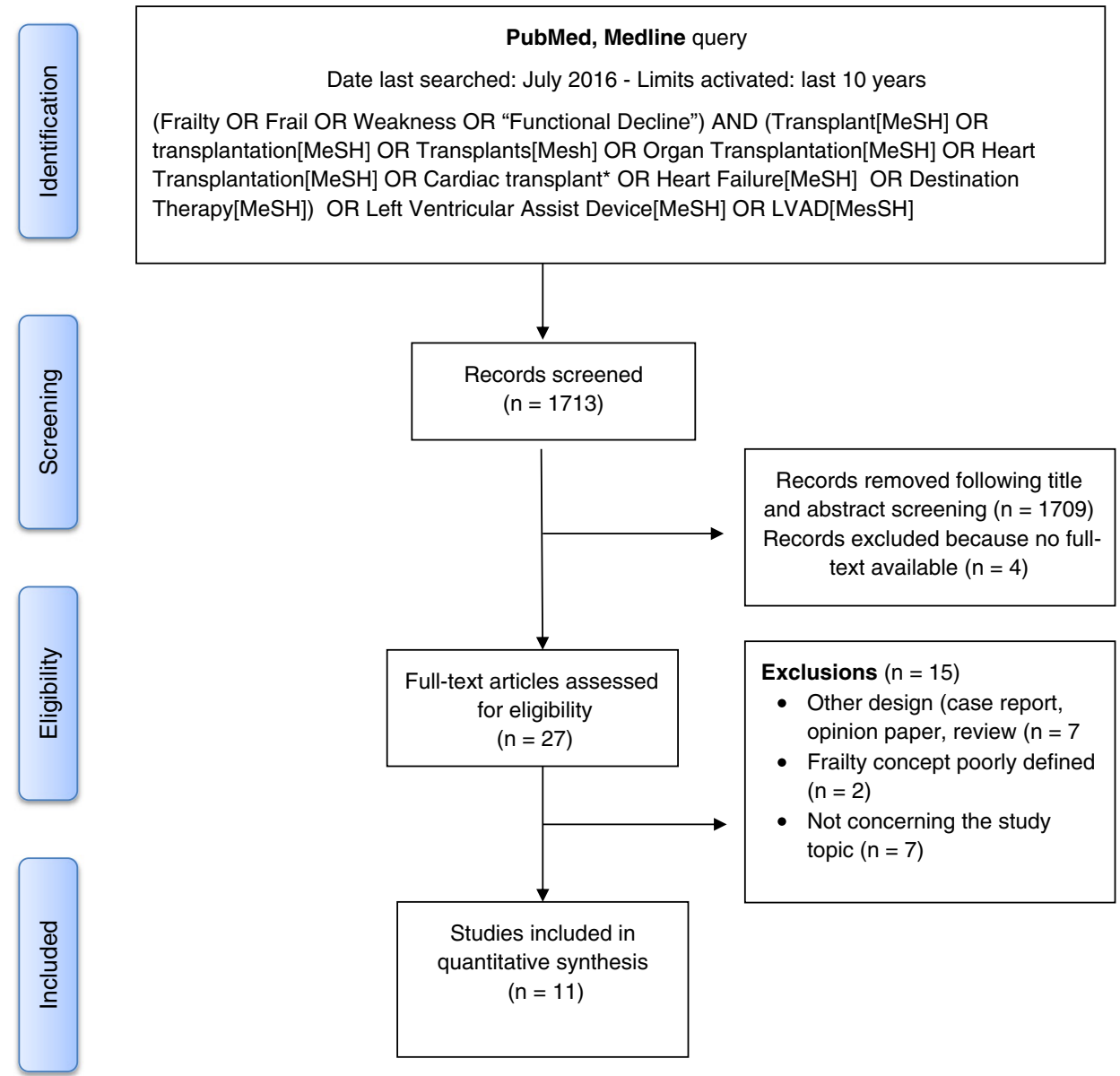

Fig. 1. Search retrieval process. 
Table 3

Summary of included articles on frailty in cardiac transplantation, including frailty in heart failure, and LVAD therapy and their impact on outcomes.

\begin{tabular}{|c|c|c|c|c|c|c|c|}
\hline $\begin{array}{l}\text { References, } \\
\text { Country }\end{array}$ & Design & Setting/Sample & $n$ & Patients & $\begin{array}{l}\text { Frailty } \\
\text { Measure }\end{array}$ & $\begin{array}{l}\text { Prevalence of } \\
\text { frailty }\end{array}$ & Clinical Outcomes \\
\hline Jha et al. [30] Australia & Prospective cohort & $\begin{array}{l}\text { Outpatients referred for } \\
\text { transplant assessment }\end{array}$ & 120 & $\begin{array}{l}53 \pm 12 \text { years; } \\
83 \% \text { males }\end{array}$ & Modified FP & $33 \%$ & Mortality HR 2.07 (95\% CI; 1.01-4.26 \\
\hline Madan et al. [31] USA & $\begin{array}{l}\text { Single-center } \\
\text { pilot study }\end{array}$ & Outpatients with CHF & 40 & $\begin{array}{l}74.9 \pm 6.5 \text { years; } \\
42 \% \text { males }\end{array}$ & FP & $65 \%$ & $\begin{array}{l}\text { All-cause hospitalization HR } 1.92(\mathrm{Cl} 95 \% 1.12-3.27 ; P=0.017) \\
\text { Non-HF hospitalizations HR } 3.31(95 \% \mathrm{Cl} 1.14-9.6 ; P=0.380) \\
\text { Mortality HR } 1.93(95 \% \mathrm{Cl} \text {; } 1.15-3.25 \\
P=0.013)\end{array}$ \\
\hline Reeves et al. [32] & $\begin{array}{l}\text { Prospective } \\
3 \text { age-matched } \\
\text { cohort }\end{array}$ & $\begin{array}{l}\text { Patients hospitalized with acute } \\
\text { decompensated heart failure } \\
\text { (HF) } \\
\text { matched with a) stable HF with } \\
\text { preserved EF, b) stable HF with } \\
\text { reduced EF, c) healthy } \\
\text { older adults }\end{array}$ & 27 & $\begin{array}{l}72.9 \pm 10 \text { years; } \\
41 \% \text { males }\end{array}$ & FP & $56 \%$ & $\begin{array}{l}\text { Severe reduction in all domains of physical function, } \\
\text { with } \approx 50 \% \text { lower in acute decompensated heart failure } \\
\text { patients than in stable heart failure or healthy older adults. }\end{array}$ \\
\hline Vidan et al. [33] & Prospective cohort & $\begin{array}{l}\text { Patients hospitalized for } \\
\text { heart failure }\end{array}$ & 450 & $\begin{array}{l}80 \pm 6 \text { years; } \\
50.5 \% \text { males }\end{array}$ & FP & $76 \%$ & $\begin{array}{l}\text { Higher risk for functional decline [OR 2.20,95\% CI 1.19-4.08], 1-year } \\
\text { all-cause mortality [HR 2.13,95\% CI 1.07-4.23] and 1-year hospital } \\
\text { readmission [OR 1.96, 95\% CI 1.14-3.34]. }\end{array}$ \\
\hline Lupon et al. [34] & Observational Study & Outpatients with CHF & 622 & $\begin{array}{l}68(29-93) \text { years; } \\
72.5 \% \text { males }\end{array}$ & $\begin{array}{l}\text { Comprehensive } \\
\text { geriatric assessment }\end{array}$ & $40 \%$ & $\begin{array}{l}\text { HR } 2.09(95 \% \text { CI } 1.11-3.92 \\
q=0.022 \text { for } 1 \text {-year mortality }\end{array}$ \\
\hline Khan et al. [35] USA & Secondary analysis & Community dwelling elders & 2825 & $\begin{array}{l}74 \pm 3 \text { years; } \\
48 \% \text { males }\end{array}$ & $\begin{array}{l}\text { Healthy aging and } \\
\text { body } \\
\text { composition \& Gill } \\
\text { index }\end{array}$ & $18 \%$ & $\begin{array}{l}\text { Moderate (HR } 1.3695 \% \text { CI } 1.08-1.710 \text { ) and severe } \\
\text { (HR } 1.88,95 \% \text { CI } 1.02-3.47 \text { ) frailty increased the risk of HF }\end{array}$ \\
\hline $\begin{array}{l}\text { McNallan et al. [36] } \\
\text { USA }\end{array}$ & Observational study & $\begin{array}{l}\text { Community dwelling } \\
\text { CHF patients }\end{array}$ & 223 & $\begin{array}{l}71 \pm 14 \text { years; } 61 \% \\
\text { males }\end{array}$ & FP and deficit index & $\begin{array}{l}\text { FP: } 21 \% \text { DI: } 0.02- \\
0.075( \pm 0.25)\end{array}$ & $\begin{array}{l}\text { Mortality; FP: HR } 2.04(95 \% \mathrm{CI} 0.99-4.16, \mathrm{q}=0 \text { ) DI: HR } 1.44 \\
(95 \% \mathrm{CI} 1.18-1.76 ; \mathrm{q}=0) \\
\text { Highly co-morbid: > } 60 \% \text { patients had a CCI C3 }\end{array}$ \\
\hline Boxer et al. [37] & Prospective cohort & Outpatients with CHF & 60 & $\begin{array}{l}78 \pm 12 \text { years; } 72 \% \\
\text { males }\end{array}$ & FP & $27 \%$ & HR $1.64(95 \%$ Cl $1.19-2.26 ; q=0.005)$ \\
\hline $\begin{array}{l}\text { Pulignano et al. [38] } \\
\text { Italy }\end{array}$ & RCT & Outpatients with $\mathrm{CHF}$ & 173 & $\begin{array}{l}\text { UC: } n=87 ; 78 \pm \\
6 \text { years; } 53 \% \text { males } \\
\text { DMP: } n=86 \\
77 \pm 6 \text { years; } 51 \% \text { males }\end{array}$ & Modified frailty score & & $\begin{array}{l}\text { Higher } 1 \text {-year mortality ( } 16.9 \text { vs. } 4.8 \% ; P<0.001) \\
\text { Higher rate of hospitalization }(20.5 \text { vs. } 13.3 \% ; P=0.01 \text { ) }\end{array}$ \\
\hline Dunlay et al. [39] & $\begin{array}{l}\text { Prospective } \\
\text { cohort study }\end{array}$ & $\begin{array}{l}\text { Patients undergoing } \\
\text { LVAD implant }\end{array}$ & 99 & $\begin{array}{l}65.1 \pm 9.4 \text { years; } \\
72 \% \text { males }\end{array}$ & Frailty deficit index & $29 \%$ & $\begin{array}{l}\text { Rehospitalization intermediate frail } \mathrm{HR} 1.70(95 \% \mathrm{Cl} 1.23-2.34) \text { and } \\
1.42 \text { ( } 95 \% \mathrm{CI} 0.98-2.06) \text { for frail. } \\
\text { Intermediate frail (HR } 1.7095 \% \mathrm{CI} 0.71-4.31 \text { ) and frail } \\
\text { (HR 3.08, 95\% CI 1.40-7.48) were at risk for death }\end{array}$ \\
\hline Chung et al. [40] & $\begin{array}{l}\text { Observational } \\
\text { cohort study }\end{array}$ & $\begin{array}{l}\text { Patients with advanced HF } \\
\text { undergoing VAD implantation }\end{array}$ & 72 & $59 \pm 2$ years; $64 \%$ males & $\begin{array}{l}\text { Hand grip strength a } \\
\text { component of FP }\end{array}$ & & $\begin{array}{l}\text { Handgrip strength of }<25 \% \text { of body weight showed increased } \\
\text { postoperative complications and mortality (bleeding } 54 \text { vs } 17 \% \text {; and } \\
\text { infections } 85 \text { vs } 54 \% \text { ), and a lower } 6 \text { months survival after the device } \\
\text { implant ( } 75.0 \text { vs } 92.9 \% \text { ) that persisted up to } 3 \text { years following LVAD } \\
\text { implant }\end{array}$ \\
\hline
\end{tabular}




\subsection{Frailty: Its usefulness in clinical transplant practice}

\subsubsection{Prevalence}

Jha et al. [30] assessed frailty in 120 patients (69\% men; mean age $53 \pm 12$ years, mean left ventricular ejection fraction $27 \pm 14 \%$ ), with advanced heart failure referred for cardiac transplantation, using a modified version of the Fried's phenotype, and found that $33 \%$ of the patients were frail. Prevalence of frailty was independent of age, gender, heart failure duration, left ventricular ejection fraction, or renal function [30]. In the study by Madan et al. [31] 65\% of patients in a heart failure clinic were found to be frail based on the Fried Frailty Phenotype. Reeves and colleagues [32] prospectively conducted a multidimensional assessment (including frailty based on Fried's phenotype) of 27 patients $\geq 60$ years of age that had been admitted with acute decompensated heart failure. The team compared study participants' functional performance to 3 age matched cohorts: 1 ) stable heart failure with preserved ejection fraction, 2) stable heart failure with reduced ejection fraction, and 3 ) healthy older adults previously enrolled as outpatients. Frailty was common, present in $>50 \%$ of participants with acute decompensated heart failure, but was rare or absent in the other cohorts ( $0 \%$ to $14 \%$ depending on the cohort) [32]. Vidán and colleagues [33] reported that $75 \%$ of non-dependent patients $\geq 70$ years of age that were hospitalized for heart failure fulfilled frailty criteria. A study by Lupon et al. [38] emphasized that frailty is more prevalent in older heart failure patients, but could also be observed in younger individuals ( $<70$ years old) with chronic heart failure.

\subsubsection{Morbidity and mortality}

Khan et al. [35], demonstrate that moderate and severe frailty increased the risk for heart failure incidence (HR 1.36; 95\% CI 1.08-1.71 and HR 1.88; $95 \%$ CI 1.02-3.47, respectively). Another study conducted by McNallen et al. [36] included community-dwelling individuals with chronic heart failure, of which over $60 \%$ had multiple co-morbidities in the presence of frailty, which increased the disease burden. Similarly, in the study by Reeves et al. [32] patients admitted to hospital with heart failure had a severe reduction in all domains of physical function, with scores on the 3 measures of physical functioning (6-min walk distance, Short Physical Performance Battery and gait speed) being approximately $50 \%$ lower in the patients with acute decompensated heart failure than in the three age-matched outpatient cohorts (two with stable heart failures and one with health older adults).

There have been few studies investigating the impact of frailty on mortality in chronic heart failure patients, and only one within cardiac transplantation [13]. Specifically, a study by Jha et al. [30] included 120 heart failure patients on the waiting list for transplantation, and reported that frailty was an independent predictor of all-cause mortality, with a mean one year survival of $79 \% \pm 5 \%$ in the non-frail group compared with $54 \% \pm 9 \%$ in the frail group $(\mathrm{P}<0.005)$. Madan et al. [31] demonstrated that the frailty status of heart failure patients was associated with mortality and all-cause hospitalization (HR 1.93; 95\% CI $1.15-3.25, \mathrm{P}=.031$ ) [31]. Boxer and colleagues [37] followed sixty community dwelling patients with heart failure $(\mathrm{EF} \leq 40 \%)$ in a heart failure center, demonstrating that frailty scores were independently predictive of mortality [HR 1.64, 95\% CI 1.19-2.26]. Vidán et al. [33] reported that frail individuals $\geq 70$ years of age who were hospitalized for heart failure showed a higher risk for functional decline [OR 2.20, 95\% CI 1.19-4.08], 1-year all-cause mortality [HR 2.13, 95\% CI 1.07-4.23] and 1-year hospital readmission [OR 1.96, 95\% CI 1.14-3.34] than the nonfrail/normal endurance group. Similarly, a study by Pulignano et al. [38] showed a significantly higher rate of hospitalization of frail individuals than in less frail patients (frailty score $<2$ ) $(21$ versus $13 \% ; P=0.01$ ). Studies in our review highlight that frailty assessment provides valuable prognostic insights in addition to existing risk prediction models.

Concomitantly, many patients with severe heart failure have noncardiac related comorbidities that render them ineligible for cardiac transplantation and are therefore considered for destination therapy.
Dunlay et al. [39] reported that pre-operative frailty assessment, using the Frailty Index, is associated with worse outcomes following LVAD implant as destination therapy. Patients who were frail at the time of an LVAD implant had an increased risk for mortality (HR 3.08; 95\% Cl 1.40-7.48). Hazard ratio for re-hospitalization was 1.70 (95\% CI 1.23-2.34) for intermediate frail patients, and 1.42 (95\% CI 0.98-2.06) in those who were frail (based on tertiles of the deficit index $>0.32=$ frail, 0.23 to $0.32=$ intermediate frailty, $<0.23=$ not frail) [39]. Findings indicate that the risk to be re-hospitalized following device implant is higher in individuals with intermediate frailty. Chung et al. [40] measured handgrip strength, a marker of frailty that is often part of the frailty scoring system, in 72 heart failure patients undergoing VAD implant. Study participants with a handgrip strength of $<25 \%$ of body weight showed increased postoperative complications and mortality (bleeding $54 \%$ vs $17 \%$; and infections $85 \%$ vs 54\%), and a lower 6 months survival after the device implant ( $75.0 \%$ vs $92.9 \%$ ) that persisted up to 3 years following VAD implant.

\section{Discussion}

The important clinical aspect for transplant professionals is that older individuals with multiple comorbidities require a better risk assessment when evaluating transplant candidacy. Frailty enables clinicians to focus on patients' biological age and has important implications for adverse health outcomes and is being endorsed by various organizations to improve quality of care [16,21]. Of importance, the magnitude of risks associated with frailty, increased comorbidities, and mortality is greater than from current risk predictions. Screening patients using an assessment tool based on the FP is endorsed by the ISHLT and can classify transplant candidates into new and clinically meaningful risk categories. In the management of patients with chronic conditions, disentangling frailty from comorbidities through the FP might be important when assessing chronically ill individuals for transplantation. FP as a screening tool to enhance risk stratification for adverse outcomes in clinical practice is feasible, since no prior clinical information is needed and it takes 10 to 15 min to complete $[18,20]$. At the same time, assessments based on the FP do not provide insights into underlying factors contributing to a patient's frailty, and thus provide limited guidance towards preventive or therapeutic interventions when frailty is identified. This is a drawback that is addressed by the FI, given its assessment of specific deficits across various domains, enabling clinicians to modify certain aspects of a patient's care to potentially improve frailty. The major disadvantage of the FI is however that it requires a comprehensive geriatric assessment for its scoring, which renders its evaluation time-consuming [41]. It is of key importance for clinicians to understand that the FP and FI cannot be considered equivalent. The optimal choice of approach depends on the purpose, e.g. whether a frailty screening for risk stratification (FP), or a more thorough frailty assessment to tailor patient care is intended (FI).

Risk stratification for frail transplant candidates and recipients, also requires evidence for feasible, effective and scalable interventions to prevent frailty, or to slow its progress. A hallmark of frailty is that the condition can deteriorate or improve over time [5,42-44]. At this point the optimal time to start an intervention to improve frailty is still not clear, especially for individuals being listed for transplantation. Given the fact that it is easier to improve small deficits, rather than larger ones it is recommended to focus on improving patient's functional status when they are pre-frail, rather than frail. Incorporating frailty screening would allow healthcare professionals to systematically identify pre-frail individuals when listing them for cardiac transplantation and initiate pre-rehabilitation. Pre-rehabilitation has shown to result in fewer complications following surgical procedures, as well as decreased hospital stay in non-transplant populations [45]. Also without intervention worsening frailty in older non-transplant populations is common. Since cardiac rehabilitation has been shown to decrease mortality and morbidity in patients with heart failure in both hospital and 
community based settings, it thus might also be ideally suited to improve an individual's frailty status prior to transplantation. When patients have been enrolled in pre-rehabilitation further frailty assessments could be conducted to capture when a patient has achieved optimal benefit from the program. Although behavioral interventions focusing on physical activity and/or exercise show potential to improve clinical outcomes [5,6,18,46-50], no interventions have focused specifically on individuals with end stage organ failure and transplant recipients to mitigate effects of frailty.

In addition to building on behavior change science, such work needs to include a better understanding of underlying pathophysiological processes that impact frailty and its interrelationship with cognitive function. Current biological frameworks of frailty etiology point to the dysregulation of several key physiological systems, including the neuroendocrine, musculoskeletal, metabolic and immune/inflammatory system [51]. Recent longitudinal studies in various cohorts of older non-transplant adults suggest the latter as a key pathway [6,52-55]. Complex alterations in the innate and adaptive immune system are hypothesized to create a state of chronic low-grade systemic inflammation, which induces frailty and a higher susceptibility for chronic conditions, disability and mortality [51]. Causality of the inflammatory pathway in frailty has to date only scarcely been explored $[49,56,57]$. Moreover, evidence on a similar etiological pathway for mild cognitive impairment (MCI) is emerging [58] with one recent study identifying that MCI (assessed using the Montreal Cognitive Assessment Tool) was present in $64 \%$ of heart failure patients who were frail pretransplant and in 33\% of those who were not physically frail [59]. Studies in patients with end-stage heart failure that incorporated cognitive assessment in the FP improve its predictive validity for adverse outcomes [59]. Research has illuminated that MCI can accelerate the development of disability, which is predictive of hospitalization and mortality [60-63]. Thus, research exploring the interrelationships of frailty and $\mathrm{MCl}$, their evolution, and joint predictive ability for negative outcomes is essential to advance frailty-screening methods [58,64]. At this point, transplant candidates with cognitive impairments are best followed up with a geriatric assessment to determine the cause of cognitive decline, followed by a personal, evidence based, multimodal intervention.

Additionally, studies show that frail patients use more healthcare resources compared to robust individuals. Frailty has therefore been recognized as a long-term condition leading to a range of adverse outcomes for individual patients and high healthcare expenses for the wider society [36,43,65-67]. Thus, research is needed to examine the impact of frailty on resource use and the cost-effectiveness of transplantation.

\section{Conclusion}

This systematic review demonstrates that frailty assessment in heart transplant candidates, as well as heart failure patients requiring mechanical circulatory support, is feasible and provides clinical prognostic value. Yet, its practical translation into transplant medicine is in its infancy. The evidence on poor outcomes of frail transplant candidates and a potential increased economic burden suggest an urgent need for transplant professionals to pay attention to the syndrome. Nevertheless, there is a need for more studies investigating frailty in the field of cardiac transplantation to allow any official recommendation for transplant list eligibility.

The authors declare no conflicts of interest. This state of the art systematic review was conducted without specific funding sources.

\section{References}

[1] Partridge JS, Harari D, Dhesi JK. Frailty in the older surgical patient: a review. Age Ageing 2012;41:142-7.

[2] Hamaker ME, Jonker JM, de Rooij SE, Vos AG, Smorenburg CH, van Munster BC. Frailty screening methods for predicting outcome of a comprehensive geriatric assessment in elderly patients with cancer: a systematic review. Lancet Oncol 2012;13:e437-44.

[3] Robinson TN, Walston JD, Brummel NE, Deiner S, Brown CHt, Kennedy M, Hurria A. Frailty for Surgeons: review of a National Institute on Aging conference on frailty for specialists. J Am Coll Surg 2015;221:1083-92.

[4] Fried LP, Tangen CM, Walston J, et al. Frailty in older adults: evidence for a phenotype. J Gerontol A Biol Sci Med Sci 2001;56:M146-56.

[5] Clegg A, Young J, Iliffe S, Rikkert MO, Rockwood K. Frailty in elderly people. Lancet 2013;381:752-62.

[6] Chen X, Mao G, Leng SX. Frailty syndrome: an overview. Clin Interv Aging 2014;9: 433-41.

[7] Mehra MR, Canter CE, Hannan MM, et al. The 2016 International Society for Heart Lung Transplantation listing criteria for heart transplantation: a 10-year update. J Heart Lung Transplant 2016;35:1-23.

[8] United Network for Organ Sharing (UNOS)-Organ Procurement and Transplantation Network (OPTN); 2014.

[9] European Renal Association-European Dialysis and Transplant Association (ERAEDTA). Annual reports; 2013.

[10] Koller M, Stampf S, Rick J, Achermann R, Steiger J. Swiss transplant cohort study report (May 2008-December 2013); 2014

[11] Goldstein DR. The graying of organ transplantation. Am J Transplant 2012;12: 2569-70.

[12] Abecassis M, Bridges ND, Clancy CJ, et al. Solid-organ transplantation in older adults: current status and future research. Am J Transplant 2012;12:2608-22.

[13] Jha SR, Ha HS, Hickman LD, Hannu M, Davidson PM, Macdonald PS, Newton PJ. Frailty in advanced heart failure: a systematic review. Heart Fail Rev 2015;20:553-60.

[14] Rodriguez-Manas L, Feart C, Mann G, et al. Searching for an operational definition of frailty: a Delphi method based consensus statement: the frailty operative definitionconsensus conference project. J Gerontol A Biol Sci Med Sci 2013;68:62-7.

[15] Gordon AL, Masud T, Gladman JR. Now that we have a definition for physical frailty, what shape should frailty medicine take? Age Ageing 2014;43:8-9.

[16] Robinson TN, Walston JD, Brummel NE, Deiner S, Brown CHt, Kennedy M, Hurria A. Frailty for surgeons: review of a National Institute on Aging conference on frailty for specialists. J Am Coll Surg 2015;221:1083-92.

[17] Fried LP, Ferrucci L, Darer J, Williamson JD, Anderson G. Untangling the concepts of disability, frailty, and comorbidity: implications for improved targeting and care. J Gerontol A Biol Sci Med Sci 2004;59:255-63.

[18] Cesari M, Gambassi G, van Kan GA, Vellas B. The frailty phenotype and the frailty index: different instruments for different purposes. Age Ageing 2014;43:10-2.

[19] Walston JD, Bandeen-Roche K. Frailty: a tale of two concepts. BMC Med 2015;13:185.

[20] Exterkate L, Slegtenhorst BR, Seyda M, et al. Frailty and transplantation. Transplantation 2015;100:727-33

[21] Chow WB, Rosenthal RA, Merkow RP, Ko CY, Esnaola NF, P. American College of Surgeons National Surgical Quality Improvement, S. American Geriatrics. Optimal preoperative assessment of the geriatric surgical patient: a best practices guideline from the American College of Surgeons National Surgical Quality Improvement Program and the American Geriatrics Society. J Am Coll Surg 2012;215:453-66.

[22] Rockwood K. What would make a definition of frailty successful? Age Ageing 2005; $34: 432-4$

[23] Jones DM, Song X, Rockwood K. Operationalizing a frailty index from a standardized comprehensive geriatric assessment. J Am Geriatr Soc 2004;52:1929-33.

[24] Rockwood K, Mitnitski A. Frailty in relation to the accumulation of deficits. J Gerontol A Biol Sci Med Sci 2007;62:722-7.

[25] Rockwood K, Hogan DB, MacKnight C. Conceptualisation and measurement of frailty in elderly people. Drugs Aging 2000;17:295-302.

[26] Rockwood K, Mitnitski A. Frailty defined by deficit accumulation and geriatric medicine defined by frailty. Clin Geriatr Med 2011;27:17-26.

[27] Rockwood K, Andrew M, Mitnitski A. A comparison of two approaches to measuring frailty in elderly people. J Gerontol A Biol Sci Med Sci 2007;62:738-43.

[28] Hii TB, Lainchbury JG, Bridgman PG. Frailty in acute cardiology: comparison of a quick clinical assessment against a validated frailty assessment tool. Heart Lung Circ 2015;24:551-6.

[29] Salter ML, Gupta N, Massie AB, et al. Perceived frailty and measured frailty among adults undergoing hemodialysis: a cross-sectional analysis. BMC Geriatr 2015;15:52-8.

[30] Jha SR, Hannu MK, Chang S, et al. The prevalence and prognostic significance of frailty in patients with advanced heart failure referred for heart transplantation. Transplantation 2016;100:429-36.

[31] Madan SA, Fida N, Barman P, et al. Frailty assessment in advanced heart failure. J Card Fail 2016;22:840-4.

[32] Reeves GR, Whellan DJ, Patel MJ, et al. Comparison of frequency of frailty and severely impaired physical function in patients $>/=60$ years hospitalized with acute decompensated heart failure versus chronic stable heart failure with reduced and preserved left ventricular ejection fraction. Am J Cardiol 2016;117:1953-8.

[33] Vidan MT, Blaya-Novakova V, Sanchez E, Ortiz J, Serra-Rexach JA, Bueno H. Prevalence and prognostic impact of frailty and its components in non-dependent elderly patients with heart failure. Eur J Heart Fail 2016;18:869-75.

[34] Lupon J, Gonzalez B, Santaeugenia S, et al. Prognostic implication of frailty and depressive symptoms in an outpatient population with heart failure. Rev Esp Cardiol 2008;61:835-42.

[35] Khan H, Kalogeropoulos AP, Georgiopoulou VV, et al. Frailty and risk for heart failure in older adults: the health, aging, and body composition study. Am Heart J 2013;166:887-94.

[36] McNallan SM, Singh M, Chamberlain AM, et al. Frailty and healthcare utilization among patients with heart failure in the community. JACC Heart Fail 2013;1:135-41.

[37] Boxer R, Kleppinger A, Ahmad A, Annis K, Hager D, Kenny A. The 6-minute walk is associated with frailty and predicts mortality in older adults with heart failure. Congest Heart Fail 2010;16:208-13. 
[38] Pulignano G, Del Sindaco D, Di Lenarda A, et al. Usefulness of frailty profile for targeting older heart failure patients in disease management programs: a costeffectiveness, pilot study. J Cardiovasc Med 2010;11:739-47.

[39] Dunlay SM, Park SJ, Joyce LD, et al. Frailty and outcomes after implantation of left ventricular assist device as destination therapy. J Heart Lung Transplant 2014;33: 359-65.

[40] Chung CJ, Wu C, Jones M, et al. Reduced handgrip strength as a marker of frailty predicts clinical outcomes in patients with heart failure undergoing ventricular assist device placement. J Card Fail 2014;20:310-5.

[41] Rubenstein LZ, Stuck AE, Siu AL, Wieland D. Impacts of geriatric evaluation and management programs on defined outcomes: overview of the evidence. J Am Geriatr Soc 1991;39:8S-16S [discussion 17S-18S].

[42] Musso CG, Jauregui JR, Macias Nunez JF. Frailty phenotype and chronic kidney disease: a review of the literature. Int Urol Nephrol 2015;47:1801-7.

[43] Harrison JK, Clegg A, Conroy SP, Young J. Managing frailty as a long-term condition. Age Ageing 2015;44:732-5.

[44] Goldraich L, Alba AC, Foroutan F, Maclver J, Ross H. Frailty phenotype is associated with decreased survival as predicted by the Seattle heart failure model in heart failure patients referred for advanced therapies. Poster presentation, annual meeting International Society for Heart and Lung Transplantation; 2015.

[45] Rumer KK, Saraswathula A, Melcher ML. Prehabilitation in our most frail surgical patients: are wearable fitness devices the next frontier? Curr Opin Organ Transplant 2016;21:188-93.

[46] Bendayan M, Bibas L, Levi M, Mullie L, Forman DE, Afilalo J. Therapeutic interventions for frail elderly patients: part II. Ongoing and unpublished randomized trials. Prog Cardiovasc Dis 2014;57:144-51.

[47] Bibas L, Levi M, Bendayan M, Mullie L, Forman DE, Afilalo J. Therapeutic interventions for frail elderly patients: part I. Published randomized trials. Prog Cardiovasc Dis 2014;57:134-43.

[48] Kelaiditi E, van Kan GA, Cesari M. Frailty: role of nutrition and exercise. Curr Opin Clin Nutr Metab Care 2014;17:32-9.

[49] Theou O, Stathokostas L, Roland KP, Jakobi JM, Patterson C, Vandervoort AA, Jones GR. The effectiveness of exercise interventions for the management of frailty: a systematic review. J Aging Res 2011;2011:569194-229.

[50] Michel JP, Cruz-Jentoft AJ, Cederholm T. Frailty, exercise and nutrition. Clin Geriatr Med 2015;31:375-87.

[51] McElhaney J, Fulop T, Pawelec G, et al. Frailty, inflammation and immunosenescence. In: Theou O, Rockwood K, editors. Frailty in aging: biological, clinical and social implications. Basel: Karger Libri; 2015.

[52] Collerton J, Martin-Ruiz C, Davies K, et al. Frailty and the role of inflammation, immunosenescence and cellular ageing in the very old: cross-sectional findings from the Newcastle 85+ study. Mech Ageing Dev 2012;133:456-66.
[53] Leng SX, Xue QL, Tian J, Walston JD, Fried LP. Inflammation and frailty in older women. J Am Geriatr Soc 2007;55:864-71.

[54] Leng SX, Xue QL, Tian J, Huang Y, Yeh SH, Fried LP. Associations of neutrophil and monocyte counts with frailty in community-dwelling disabled older women: results from the Women's Health and Aging Studies I. Exp Gerontol 2009;44:511-6.

[55] Li H, Manwani B, Leng SX. Frailty, inflammation, and immunity. Aging Dis 2011;2: 466-73.

[56] Gale CR, Baylis D, Cooper C, Sayer AA. Inflammatory markers and incident frailty in men and women: the English Longitudinal Study of Ageing. Age (Dordr) 2013;35: 2493-501.

[57] Singer JP, Diamond JM, Gries CJ, et al. Frailty phenotypes, disability, and outcomes in adult candidates for Lung transplantation. Am J Respir Crit Care Med 2015;192: 1325-34.

[58] Halil M, Cemal Kizilarslanoglu M, Emin Kuyumcu M, Yesil Y, Cruz Jentoft AJ. Cognitive aspects of frailty: mechanisms behind the link between frailty and cognitive impairment. J Nutr Health Aging 2015;19:276-83.

[59] Jha SR, Hannu MK, Gore K, et al. Cognitive impairment improves the predictive validity of physical frailty for mortality in patients with advanced heart failure referred for heart transplantation. J Heart Lung Transplant 2016;35:1092-100.

[60] Auyeung TW, Lee JS, Kwok T, Woo J. Physical frailty predicts future cognitive decline - a four-year prospective study in 2737 cognitively normal older adults. J Nutr Health Aging 2011;15:690-4.

[61] Jacobs JM, Cohen A, Ein-Mor E, Maaravi Y, Stessman J. Frailty, cognitive impairment and mortality among the oldest old. J Nutr Health Aging 2011;15:678-82.

[62] Drame M, Novella JL, Jolly D, et al. Rapid cognitive decline, one-year institutional admission and one-year mortality: analysis of the ability to predict and inter-too agreement of four validated clinical frailty indexes in the SAFEs cohort. J Nutr Health Aging 2011;15:699-705.

[63] Yassuda MS, Lopes AJ, Cachioni M, Falcao DV, Batistoni SS, Guimaraes VA. Frailty criteria and cognitive performance are related: data from the FIBRA study in Ermelino Matarazzo, São Paulo, Brazil. J Nutr Health Aging 2012;16:55-61.

[64] Robertson DA, Savva GM, Kenny RA. Frailty and cognitive impairment-a review of the evidence and causal mechanisms. Ageing Res Rev 2013;12:840-51.

[65] Lyndon H. Reframing frailty as a long-term condition. Nurs Older People 2015;27:32-9.

[66] Ilinca S, Calciolari S. The patterns of health care utilization by elderly Europeans: frailty and its implications for health systems. Health Serv Res 2015;50:305-20.

[67] Rapp T, Sirven N. The dynamics of hospital use among older people: evidence for Europe using SHARE data. Document de Travail No 2014/01; 2014 [http://lare-efi. u-bordeaux4.fr/IMG/pdf/SirvenRapp2014.pdf].

[68] Roberts HC, Denison HJ, Martin HJ, Patel HP, Syddall H, Cooper C, Sayer AA. A review of the measurement of grip strength in clinical and epidemiological studies: towards a standardised approach. Age Ageing 2011;40:423-9. 